\title{
Prediction of Solvent Diffusivities in Amorphous Polymers by Free-Volume Theory: Group Contribution and PALS Methods
}

\author{
By Hong-ling LV, ${ }^{1, *}$ Bao-guo $W A N G,{ }^{2}$ and Ying KONG ${ }^{1}$
}

A group contribution-based model was proposed to predict solvent diffusion coefficients in amorphous polymers with the free-volume conceptual framework. Based on the van der Waals volume of polymer structural units, this model provides a novel way to estimate the hole free volume of polymer in its rubbery state, which is the effective space for solvent jump. All the parameters with respect to polymer can be determined by group contribution method using the knowledge of polymer structure, and no adjustable parameters are required. Calculated solvent diffusion coefficients in polymers were in good agreement with published experimental results. A linear dependence was found between logarithm of infinite dilution diffusion coefficient of various organic solvents and hole free volume in four common polymers. In addition, the hole size distribution from positron annihilation lifetime spectroscopy (PALS) measurements was investigated to reaffirm the reliability of this model, on the basis that the ratio of polymer hole free volume to total free volume from microscopic viewpoint should be equivalent to that from macroscopic viewpoint.

KEY WORDS: Diffusion Coefficient / Amorphous Polymer / Free Volume / Group Contribution / Positron Annihilation Lifetime

Spectroscopy (PALS) /

The diffusion behaviors of organic solvents in polymers have been involved in a variety of technologies: membrane separation, coatings, drug delivery and so on. In these applications, it is necessary to estimate solvent diffusivity, which usually governs the transport process. Over the past decades, an extensive amount of work has been devoted to the development of theoretical models that exhibit good correlations of solvent diffusion coefficient in polymer solutions. ${ }^{1}$ The most successful models are based on the concept of free volume, ${ }^{2-13}$ which is defined as the unoccupied volume surrounding the hard core volume of matter, as well known in polymer science. This concept was first proposed by Cohen and Turnbull for the case of molecular diffusion in liquid systems, ${ }^{14,15}$ introduced by Fujita for the description of migration in polymer-solvent mixtures, ${ }^{2,5}$ and extensively investigated by Vrentas and Duda for both self- and mutualdiffusion in polymer-solvent systems. ${ }^{3,4,6-11}$ According to the free-volume theory, it is assumed that the free volume is the major factor controlling the diffusion rate of molecules. The Vrentas-Duda model offers a significant advantage that there are no adjustable constants and most can be determined from pure component data. Unfortunately, in order to quantify the free volume provided by polymer, many efforts have been given by fitting experimental results from polymer viscoelasticity, meaning a great deal of time and cost consumption. ${ }^{6-9,11-13}$ In our previous work, theoretical equations-ofstate (EOSs) (i.e., hole theory and lattice-fluid theory) were employed to determine the free volume of polymer, and measurements of viscoelasticity can be avoided. ${ }^{16-18}$ These EOSs have a statistical-mechanical nature and a reduced dimensionless form to describe volumetric properties for polymer liquids. However, it is considered that modification of the free-volume theory is not limited to the EOS-approach. Moreover, the relation between detailed information of the atomic-scale holes, which collectively constitute the free volume in polymer, and solvent diffusivity still remains uncertainty. In this paper, an interesting correlation between volumetric properties and van der Waals volume will be employed to express the polymer free volume available for solvent transport and thus predict solvent diffusivities. In addition, published results from positron annihilation lifetime spectroscopy (PALS) measurements will be used to evaluate the modification.

\section{THEORETICAL}

\section{Original Free-Volume Theory}

As defined by Vrentas and Duda, the volume of an amorphous polymer consists of three parts: core volume, interstitial free volume and hole free volume. ${ }^{3}$ Only the third part is effective for molecular jump. For a homogeneous polymer above its glass transition temperature, the solvent diffusivity is dominated by the amount of hole free volume, and the effect of activation energy can be neglected. The infinite dilution diffusion coefficient $D^{\infty}$ is determined as follows: $:^{6,9,13}$

$$
\begin{aligned}
D^{\infty} & =D_{0} \exp \left(-\frac{E^{*}}{R T}\right) \exp \left(-\frac{\xi \hat{V}_{2}^{*}}{\hat{V}_{\mathrm{FH} 2}}\right) \\
& =D_{01} \exp \left(-\frac{\xi \hat{V}_{2}^{*}}{\hat{V}_{\mathrm{FH} 2}}\right)
\end{aligned}
$$

Here, $\hat{V}_{2}^{*}$ is the critical hole free volume for polymer segment motion, which is regarded as the occupied volume at

\footnotetext{
${ }^{1}$ State Key Laboratory of Heavy Oil Processing, China University of Petroleum (East China), Dongying 257601, the Peoples's Republic of China ${ }^{2}$ Department of Chemical Engineering, Tsinghua University, Beijing 100084, the Peoples's Republic of China

*To whom correspondence should be addressed (Tel: +86-532-86981812, E-mail: honglinglv@ 163.com).
} 
absolute zero. $D_{01}$ is a constant pre-exponential factor related to the critical energy that a molecule needs to overcome the intermolecular interactions. This parameter has been determined and reported for about 50 kinds of common solvents from a nonlinear regression of the Dullien equation. ${ }^{9,11}$ The coupling parameter $\xi$ is defined as the ratio of critical molar volume of solvent jumping unit to that of polymer jumping unit. In the estimation of $\xi$ without adjustable parameters, an empirical equation has been widely used in which the input parameters are from group contribution method. ${ }^{9} \hat{V}_{\mathrm{FH} 2}$ is the hole free volume of polymer, which has to be obtained from measurements of polymer viscoelasticity according to a number of different schemes. ${ }^{6-9,11-13}$

\section{Modification of Free-Volume Theory Based on Group Contribution}

Hole Free Volume of Polymer. According to the free-volume theory, the hole free volume of polymer is regarded as an alternate portion in the Williams-Landel-Ferry (WLF) theory. ${ }^{3,4,6,9,19}$ Consequently, $\hat{V}_{\mathrm{FH} 2}$ can be considered as the sum of two parts: the free volume at the glass transition, and the excess free volume caused by the difference between expansivities above and below the glass transition temperature. ${ }^{19,20}$ In essence, the expansivities of a polymer in both amorphous glassy and rubbery states show a slight gradual increase with temperature. Compared with the jump in expansivity on passing through the glass transition, it is reasonable to ignore this increase and to represent the expansivities as constants. From this it follows that:

$$
\hat{V}_{\mathrm{FH} 2}=\frac{\tilde{V}\left(T_{\mathrm{g} 2}\right) f_{\mathrm{g}}+\left(E_{1}-E_{\mathrm{g}}\right)\left(T-T_{\mathrm{g} 2}\right)}{M_{2}}
$$

Here, $M_{2}$ is the molar weight of polymer structural unit; $T_{\mathrm{g} 2}$ is the glass transition temperature of polymer, which can be determined by group contribution method; ${ }^{21} \tilde{V}\left(T_{\mathrm{g} 2}\right)$ is the molar volume of polymer at $T_{\mathrm{g} 2} ; f_{\mathrm{g}}$ is the fractional free volume at $T_{\mathrm{g} 2}$, the value of which is usually treated as 0.025 for the great majority of polymers $;^{20,22,23} E_{1}\left(=\left(\partial \tilde{V}_{1} / \partial T\right)_{\mathrm{P}}\right)$ and $E_{\mathrm{g}}\left(=\left(\partial \tilde{V}_{\mathrm{g}} / \partial T\right)_{\mathrm{P}}\right)$ are the molar thermal expansivities above and below $T_{\mathrm{g} 2}$, respectively.

On the basis of molar volume of different polymers at room temperature, van Krevelen has obtained some simple relationships: ${ }^{21}$

$$
E_{1}=1.0 \times 10^{-3} \tilde{V}_{\mathrm{W}}, E_{\mathrm{g}}=0.45 \times 10^{-3} \tilde{V}_{\mathrm{W}}
$$

and

$$
\tilde{V}\left(T_{\mathrm{g} 2}\right)=\left(1.3+1.0 \times 10^{-3} T_{\mathrm{g} 2}\right) \tilde{V}_{\mathrm{W}}
$$

where $\tilde{V}_{\mathrm{W}}$ represents the molar van der Waals volume of structural unit in polymer, which is equal to the sum of functional group volume $\tilde{v}_{\mathrm{W}}$ in this unit, i.e., $\tilde{V}_{\mathrm{W}}=\sum_{i}\left(\tilde{v}_{\mathrm{W}}\right)_{i}$. The van der Waals volume of a molecule is the occupied space impenetrable to other molecules with normal energies. The contributions of this kind of volume for structural groups have been published as constant in literature, ${ }^{21}$ and the values for some common groups are listed in Table I. Table II illustrates
Table I. Mass and van der Waals volume of group increments ${ }^{21}$

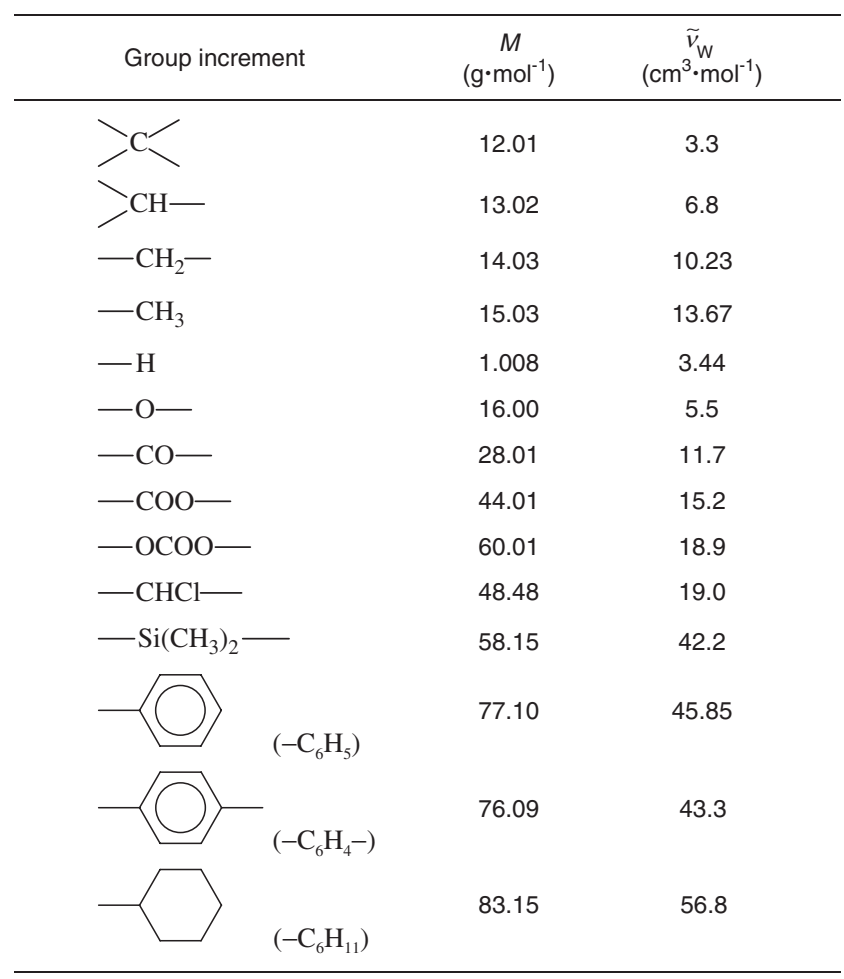

the classification of structural units and basic physical properties for commonly encountered polymers.

By substituting eqs 3 and 4 into eq 2, the polymer hole free volume in the homogenous rubbery state can be expressed as

$$
\hat{V}_{\mathrm{FH} 2}=\frac{10^{-3} \tilde{V}_{\mathrm{W}}}{M_{2}}\left(32.5+0.55 T-0.525 T_{\mathrm{g} 2}\right)
$$

This group-contribution procedure starts from the definition of hole free volume and allows the prediction with the knowledge of polymer structure as input. While much work developed approaches from viscoelastic data, ${ }^{6-13}$ or EOSs, ${ }^{16-18}$ the characteristic parameters of which have to be obtained from pressure-volume-temperature (PVT) data for polymers inspected. The amount of such available experimental data is insufficient, especially for polymers containing non-hydrogen atoms, rings or double bonds, or novel polymeric structures which have not yet been synthesized at present. Since the van der Waals volume is one of the fundamental properties of matter, this approach is more common and provides the prediction without being limited by the availability of group contributions.

Critical Volume for Polymer Jumping Segment. The parameter $\hat{V}_{2}^{*}$ can be estimated as the specific volume of polymer at absolute zero, i.e., $\hat{V}_{2}^{*}=\hat{V}_{\mathrm{o}}(0) .{ }^{6,9}$ In the Vrentas-Duda model, Sugden's method was used. ${ }^{6-13}$ Here, we employ Bondi's group contribution treatment, in which $\tilde{V}_{\mathrm{o}}(0)$ can be well approximated by $1.3 \tilde{V}_{\mathrm{W}} .^{21,24}$ The factor of 1.3 , which is assumed to be a universal constant effective for all groups and 
Table II. Van der Waals volumes and other physical properties of polymers ${ }^{9,13,21}$

\begin{tabular}{|c|c|c|c|c|c|c|}
\hline Polymer & Abbr. & Groups & $\begin{array}{c}M_{2} \\
\left(\mathrm{~g} \cdot \mathrm{mol}^{-1}\right)\end{array}$ & $\begin{array}{c}\rho_{2} \\
\left(\mathrm{~g} \cdot \mathrm{cm}^{-3}\right)\end{array}$ & $\begin{array}{l}T_{\mathrm{g} 2} \\
(\mathrm{~K})\end{array}$ & $\begin{array}{c}\tilde{V}_{\mathrm{W}} \\
\left(\mathrm{cm}^{3} \cdot \mathrm{mol}^{-1}\right)\end{array}$ \\
\hline Poly(methyl acrylate) & PMA & $\mathrm{CH}_{3}(1) ; \mathrm{CH}_{2}(1) ; \mathrm{CH}(1) ; \mathrm{COO}(1)$ & 86.1 & 1.22 & 276 & 45.90 \\
\hline Poly(ethyl acrylate) & PEA & $\mathrm{CH}_{3}(1) ; \mathrm{CH}_{2}(2) ; \mathrm{CH}(1) ; \mathrm{COO}(1)$ & 100.1 & 1.12 & 250 & 56.13 \\
\hline Poly(butyl acrylate) & PBA & $\mathrm{CH}_{3}(1) ; \mathrm{CH}_{2}(4) ; \mathrm{CH}(1) ; \mathrm{COO}(1)$ & 128.2 & 1.07 & 218 & 76.59 \\
\hline Poly(hexyl acrylate) & PHA & $\mathrm{CH}_{3}(1) ; \mathrm{CH}_{2}(6) ; \mathrm{CH}(1) ; \mathrm{COO}(1)$ & 156.2 & 1.02 & 213 & 97.05 \\
\hline Poly(lauryl acrylate) & PLA & $\mathrm{CH}_{3}(1) ; \mathrm{CH}_{2}(12) ; \mathrm{CH}(1) ; \mathrm{COO}(1)$ & 240.4 & 0.96 & 243 & 158.43 \\
\hline Poly(isopropyl acrylate) & PiPA & $\mathrm{CH}_{3}(2) ; \mathrm{CH}_{2}(1) ; \mathrm{CH}(2) ; \mathrm{COO}(1)$ & 114.1 & 1.11 & 264 & 66.37 \\
\hline Poly(isobutyl acrylate) & PiBA & $\mathrm{CH}_{3}(2) ; \mathrm{CH}_{2}(2) ; \mathrm{CH}(2) ; \mathrm{COO}(1)$ & 128.2 & 1.07 & 230 & 76.60 \\
\hline Poly(cyclohexyl acrylate) & $\mathrm{PcHA}$ & $\mathrm{C}_{6} \mathrm{H}_{11}(1) ; \mathrm{CH}_{2}(1) ; \mathrm{CH}(1) ; \mathrm{COO}(1)$ & 154.2 & 1.10 & 292 & 89.03 \\
\hline Poly(2-ethylhexyl acrylate) & PEHA & $\mathrm{CH}_{3}(2) ; \mathrm{CH}_{2}(6) ; \mathrm{CH}(2) ; \mathrm{COO}(1)$ & 184.3 & 0.99 & 218 & 117.52 \\
\hline Poly(methyl methacrylate) & PMMA & $\mathrm{CH}_{3}(2) ; \mathrm{CH}_{2}(1) ; \mathrm{C}(1) ; \mathrm{COO}(1)$ & 100.1 & 1.17 & 381 & 56.07 \\
\hline Poly(ethyl methacrylate) & PEMA & $\mathrm{CH}_{3}(2) ; \mathrm{CH}_{2}(2) ; \mathrm{C}(1) ; \mathrm{COO}(1)$ & 114.1 & 1.12 & 335 & 66.30 \\
\hline Poly(butyl methacrylate) & PBMA & $\mathrm{CH}_{3}(2) ; \mathrm{CH}_{2}(4) ; \mathrm{C}(1) ; \mathrm{COO}(1)$ & 142.2 & 1.05 & 300 & 86.76 \\
\hline Poly(hexyl methacrylate) & PHMA & $\mathrm{CH}_{3}(2) ; \mathrm{CH}_{2}(6) ; \mathrm{C}(1) ; \mathrm{COO}(1)$ & 170.3 & 1.01 & 268 & 107.22 \\
\hline Poly(octyl methacrylate) & POMA & $\mathrm{CH}_{3}(2) ; \mathrm{CH}_{2}(8) ; \mathrm{C}(1) ; \mathrm{COO}(1)$ & 198.3 & 0.97 & 253 & 127.68 \\
\hline Poly(lauryl methacrylate) & PLMA & $\mathrm{CH}_{3}(2) ; \mathrm{CH}_{2}(12) ; \mathrm{C}(1) ; \mathrm{COO}(1)$ & 254.4 & 0.95 & 208 & 168.60 \\
\hline Poly(2-ethylhexyl methacrylate) & PEHMA & $\mathrm{CH}_{3}(3) ; \mathrm{CH}_{2}(6) ; \mathrm{CH}(1) ; \mathrm{C}(1) ; \mathrm{COO}(1)$ & 198.3 & 0.98 & 284 & 127.69 \\
\hline Poly(dimethylsiloxane) & PDMS & $\mathrm{Si}\left(\mathrm{CH}_{3}\right)_{2}(1) ; \mathrm{O}(1)$ & 74.2 & 0.98 & 150 & 47.70 \\
\hline Poly( $\alpha$-methylstyrene) & $\mathrm{P} \alpha \mathrm{MS}$ & $\mathrm{C}_{6} \mathrm{H}_{4}(1) ; \mathrm{CH}_{3}(1) ; \mathrm{CH}_{2}(1) ; \mathrm{CH}(1)$ & 118.2 & 1.06 & 445 & 74.00 \\
\hline Polycarbonate & PC & $\mathrm{C}_{6} \mathrm{H}_{4}(2) ; \mathrm{CH}_{3}(2) ; \mathrm{COO}(1) ; \mathrm{C}(1) ; \mathrm{O}(1)$ & 254.3 & 1.31 & 418 & 137.94 \\
\hline Poly(isobutylene) & PIB & $\mathrm{CH}_{3}(2) ; \mathrm{CH}_{2}(1) ; \mathrm{C}(1)$ & 56.1 & 0.84 & 205 & 40.87 \\
\hline Polypropylene & $\mathrm{PP}$ & $\mathrm{CH}_{3}(1) ; \mathrm{CH}_{2}(1) ; \mathrm{CH}(1)$ & 42.1 & 0.85 & 253 & 30.70 \\
\hline Poly(p-methylstyrene) & PpMS & $\mathrm{C}_{6} \mathrm{H}_{4}(1) ; \mathrm{CH}_{3}(1) ; \mathrm{CH}_{2}(1) ; \mathrm{CH}(1)$ & 118.2 & 1.04 & 380 & 74.00 \\
\hline Polystyrene & PS & $\mathrm{C}_{6} \mathrm{H}_{5}(1) ; \mathrm{CH}_{2}(1) ; \mathrm{CH}(1)$ & 104.2 & 1.05 & 373 & 62.88 \\
\hline Poly(vinyl acetate) & PVAc & $\mathrm{CH}_{3}(1) ; \mathrm{CH}_{2}(1) ; \mathrm{CH}(1) ; \mathrm{COO}(1)$ & 86.1 & 1.19 & 305 & 45.90 \\
\hline
\end{tabular}

structures, accounts for the fact that the zero point volume is greater than the molecular volume. Consequently, it can be given that

$$
\hat{V}_{2}^{*}=1.3 \tilde{V}_{\mathrm{W}} / M_{2}
$$

\section{Correlation Between PALS and Free-Volume Theory}

The free volume in polymer appears as the sum of many atomic-scale holes. PALS is a unique technique to detect these holes in polymers, since positronium (Ps) atoms are preferentially trapped in holes. ${ }^{25,26}$ It is obvious that only the holes, the volume of which is larger than the critical volume for jump, are available for molecular transport.

From macro viewpoint, the total volume of holes probed by $o$-Ps can be considered approximately as the volume of vacancies described by the Simha-Somcynsky hole theory EOS, $(1-y) V .^{27,28}$ Therefore, the ratio of polymer hole free volume to total free volume via PALS can be determined as $F=\hat{V}_{\mathrm{FH} 2} /[(1-y) V]$.

From micro viewpoint, an expression for the free-volume probability density function from PALS, $V \operatorname{pdf}\left(V_{\mathrm{f}}\right)$, has been developed by assuming spherical holes. ${ }^{25}$ From this follows the cumulative distribution of holes effective for transport as $C\left(V_{\mathrm{f}} \geq V_{\mathrm{f}, \mathrm{c}}\right)=\int_{V_{\mathrm{f}, \mathrm{c}}}^{V_{\mathrm{f} \text { ax }}} V \operatorname{pdf}\left(V_{\mathrm{f}}\right) \mathrm{d} V_{\mathrm{f}}$. Here, $V_{\mathrm{f}, \mathrm{c}}$ is the critical hole volume, which is theoretically from $V_{\mathrm{f}, \mathrm{c}}=\hat{V}_{2}^{*} M_{2} / N_{\mathrm{A}}$ ( $N_{\mathrm{A}}$-Avogadro constant).

It is reasonable that the ratio of polymer hole free volume to total free volume from microscopic view equals to that from macroscopic view. Therefore, the relation $C\left(V_{\mathrm{f}} \geq V_{\mathrm{f}, \mathrm{c}}\right)=F$ can be used to test the reliability of modification for the freevolume theory.

\section{RESULTS AND DISCUSSION}

\section{Prediction of Infinite Dilution Diffusion Coefficient}

Figures 1-3 show the comparison between calculated and experimental infinite dilution diffusion coefficients in polystyrene-benzene, poly(vinyl acetate)-acetone and poly(vinyl acetate)-methyl acetate systems. In the calculation, $\xi$ and $D_{01}$ were determined as in the Vrentas-Duda model, ${ }^{9,11-13}$ and the values were shown in corresponding figures. The predictions are consistent with the experimental values over a considerable temperature range. This result can be attributed to the appropriate estimation of hole free volume and critical volume

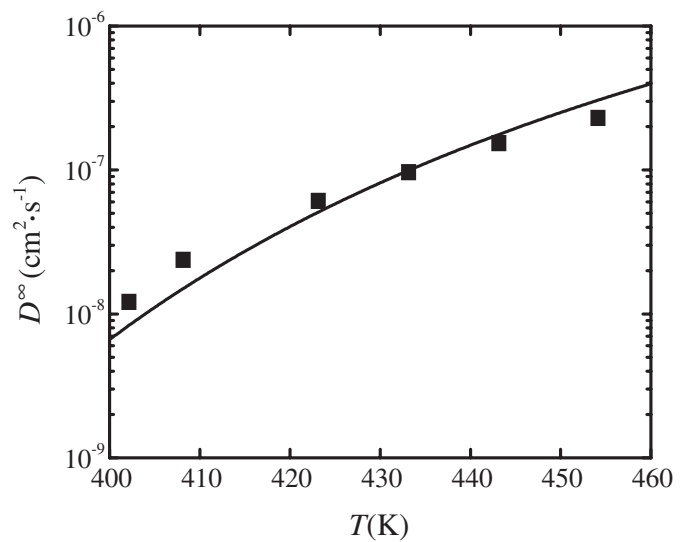

Figure 1. Comparison of calculated infinite dilution diffusion coefficients of benzene in polystyrene with experimental data $^{29} \quad(\xi=0.485$, $D_{01}=4.47 \times 10^{-4} \mathrm{~cm}^{2} \cdot \mathrm{s}^{-1}$, from ref 9 ). 


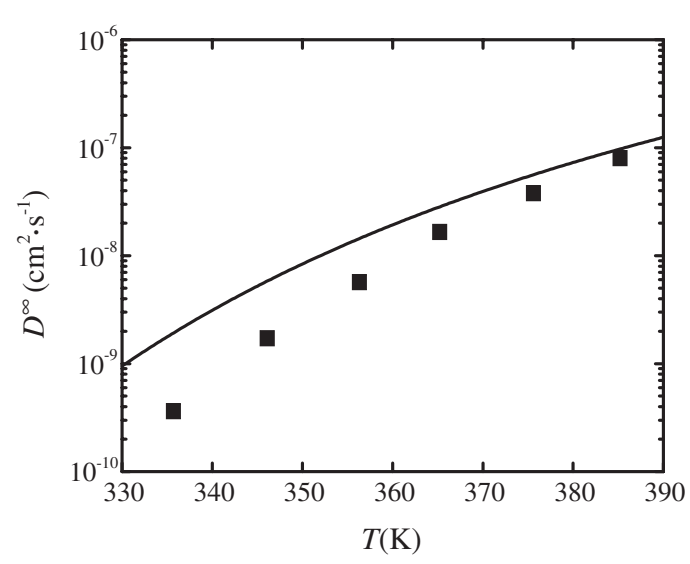

Figure 2. Comparison of calculated infinite dilution diffusion coefficients of acetone in poly(vinyl acetate) with experimental data ${ }^{30}(\xi=0.532$, $D_{01}=3.60 \times 10^{-4} \mathrm{~cm}^{2} \cdot \mathrm{s}^{-1}$, from ref 9 ).

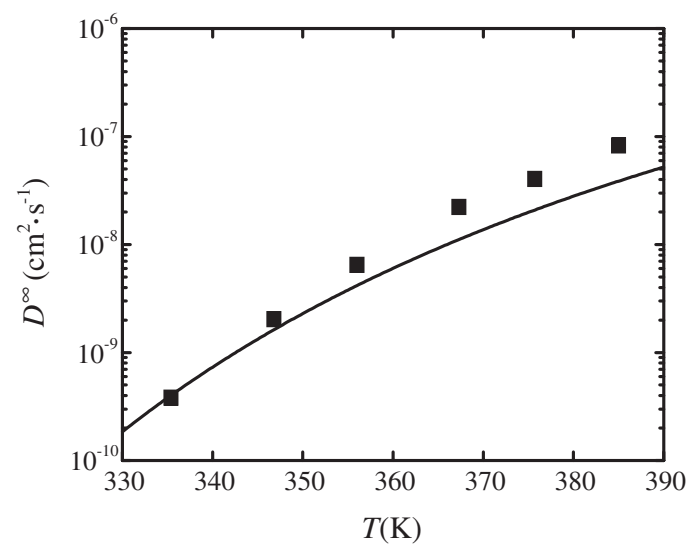

Figure 3. Comparison of calculated infinite dilution diffusion coefficients of methyl acetate in poly(vinyl acetate) with experimental data ${ }^{30}$ $\left(\xi=0.616, D_{01}=5.23 \times 10^{-4} \mathrm{~cm}^{2} \cdot \mathrm{s}^{-1}\right.$, from ref 9$)$.

for polymer jumping unit. The infinite dilution diffusion coefficients increase with increasing temperature, due to the variation of polymer segment dynamic vibration and increasing space among polymer chains. Meanwhile, the bond lengths between atoms in molecular structure are essentially independent of temperature. This work uses the van der Waals volume to express these thermal and dynamic properties of polymer segments, and provides a simple and potentially useful theoretical route particularly for non-standard polymer systems. By contrast, the viscosity-temperature or PVT data must be collected and analyzed in the previous models. ${ }^{6-13,16-18}$

The introduction of van der Waals volume into the model exhibits advantages from a design point of view, since all the parameters with respect to polymer can be determined with the knowledge of polymer structural unit. The van der Waals volume is a basic physical quantity of matter, meaning that this group contribution approach is not limited by group values as in the previous study. ${ }^{18}$ The parameters $\xi$ and $D_{01}$ are obtained with the methods in ref 9 , in which sensitivity analysis is also given. Those evaluation methods of $\xi$ and $D_{01}$ are common treatment for the determination of solvent diffusion coefficient

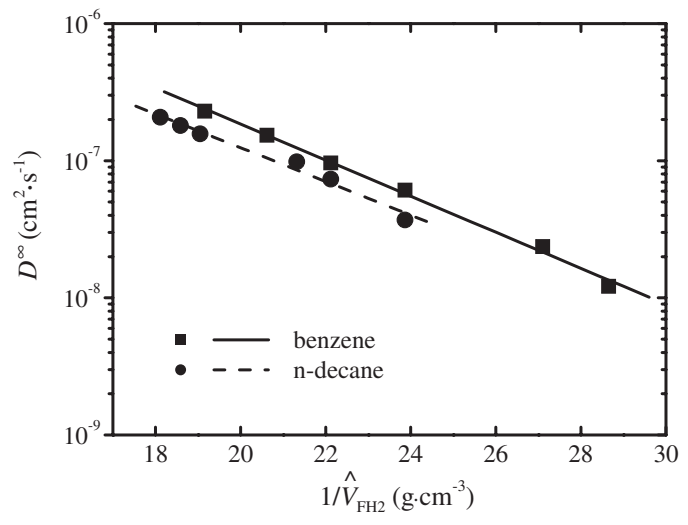

Figure 4. Correlation between solvent infinite dilution diffusion coefficient ${ }^{29}$ and reciprocal of polymer hole free volume in polystyrene.

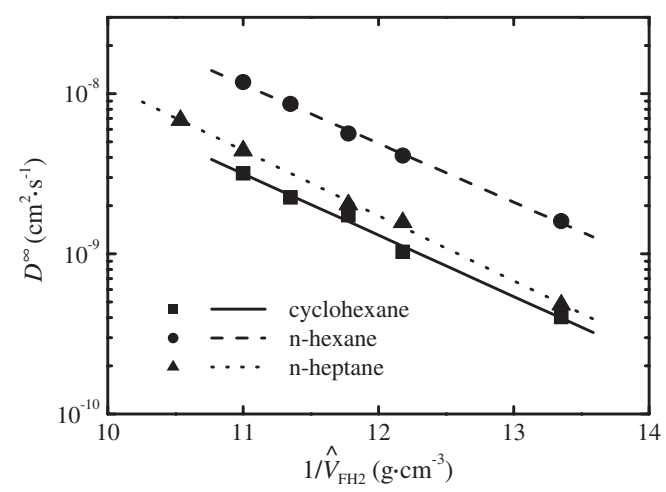

Figure 5. Correlation between solvent infinite dilution diffusion coefficient ${ }^{32,33}$ and reciprocal of polymer hole free volume in polyisobutylene.

in most studied polymer-solvent systems, ${ }^{9-13}$ and might possibly be improved by combining these two parameters with the van der Waals volume of polymer structural units.

It should be emphasized that the influence of solvent size on diffusivity is primarily reflected through the parameter $\xi$ in the condition of vanishing solvent concentration. This parameter is influenced by size and configuration of both solvent and polymer, and thus it seems preferable to get intensive comprehension from microscopic view, such as molecular modeling. ${ }^{31}$ Further research will be performed considering the microstructure of molecules.

\section{Relation Between Polymer Hole Volume and Diffusion Coefficient}

Plots of experimental infinite dilution diffusion coefficient versus inverse polymer hole free volume were constructed in order to further explore the relation between thermodynamic properties of polymer and solvent diffusivities. It is evident from Figures 4-8 that there is a fairly good linear correlation between $\log D^{\infty}$ and $1 / \hat{V}_{\mathrm{FH} 2}$ for penetrants including methanol, acetates, alkanes and aromatics in polystyrene, polyisobutylene, poly(vinyl acetate) and poly(methyl methacrylate). This correlation agrees with the free-volume theory, and can be expressed in the following form equivalent to eq 1 : 


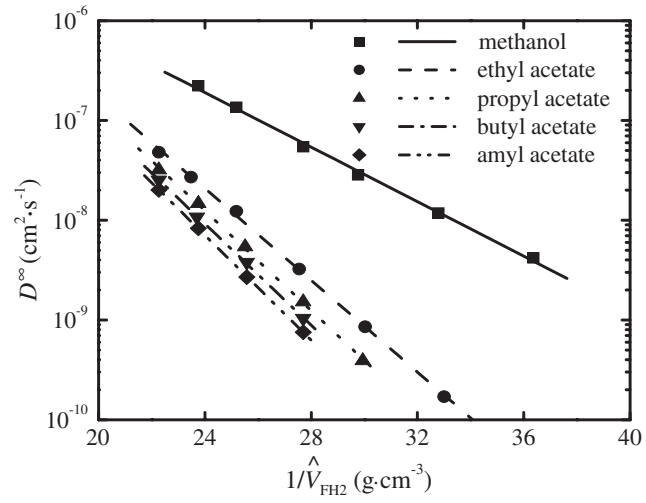

Figure 6. Correlation of infinite dilution diffusion coefficient of methanol and acetates $^{30}$ with reciprocal of polymer hole free volume in poly(vinyl acetate).

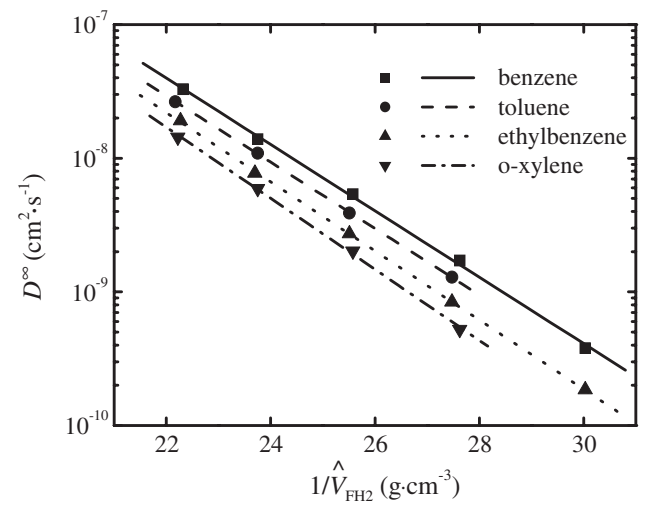

Figure 7. Correlation between infinite dilution diffusion coefficient of aromatic solvents ${ }^{30}$ and reciprocal of polymer hole free volume in poly(vinyl acetate).

$$
\log D^{\infty}=A-\frac{B}{\hat{V}_{\mathrm{FH} 2}}
$$

Here, $A$ and $B$ are constants for certain penetrant, which relate to $D_{01}$ and $\xi \hat{V}_{2}^{*}$, respectively. Eq 7 has been frequently used to test the estimation of polymer hole free volume provided for gas permeation, although the estimation method is not the same as for polymer-solvent systems. ${ }^{34}$

\section{Analysis from PALS Results}

For polystyrene at $403 \mathrm{~K}, C\left(V_{\mathrm{f}} \geq V_{\mathrm{f}, \mathrm{c}}\right)$ can be determined using the reported hole size distribution from PALS ${ }^{25}$ the value of which is $\sim 40.6 \%$ (Figure 9 ). Here, $V_{\mathrm{f}, \mathrm{c}}$ is calculated as $\sim 135.7 \AA^{3}$, corresponding to $\hat{V}_{2}^{*}=1.3 \tilde{V}_{\mathrm{W}} / M_{2}=0.784$ $\mathrm{cm}^{3} \cdot \mathrm{g}^{-1}$ (Table II). The characteristic parameters of SimhaSomcynsky EOS were from reference, ${ }^{35}$ and the value of $F$ at $403 \mathrm{~K}$ was calculated as $\sim 47.2 \%$, somewhat lager than that of $C\left(V_{\mathrm{f}} \geq V_{\mathrm{f}, \mathrm{c}}\right)$. This derivation is acceptable, and may arise from the assumption of constant thermal expansivities in the estimation of $\hat{V}_{\mathrm{FH} 2}$. It should be admitted that all group contribution methods unavoidably lead to various degrees of discrepancy, since properties are determined by additive rule of groups.

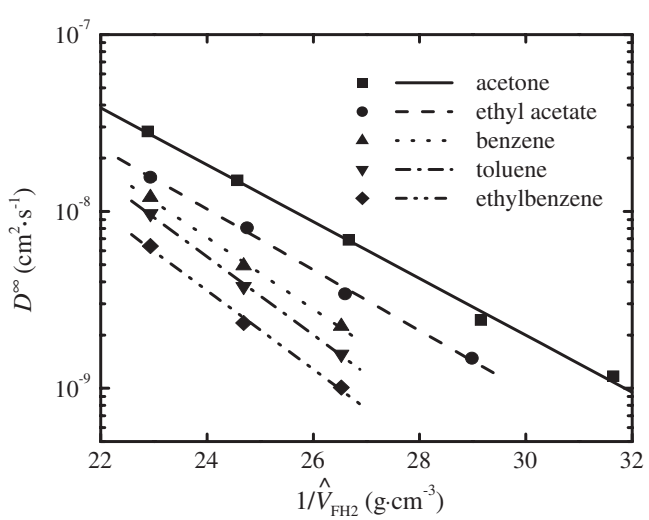

Figure 8. Correlation between solvent infinite dilution diffusion coefficient ${ }^{30}$ and reciprocal of polymer hole free volume in poly(methyl methacrylate).

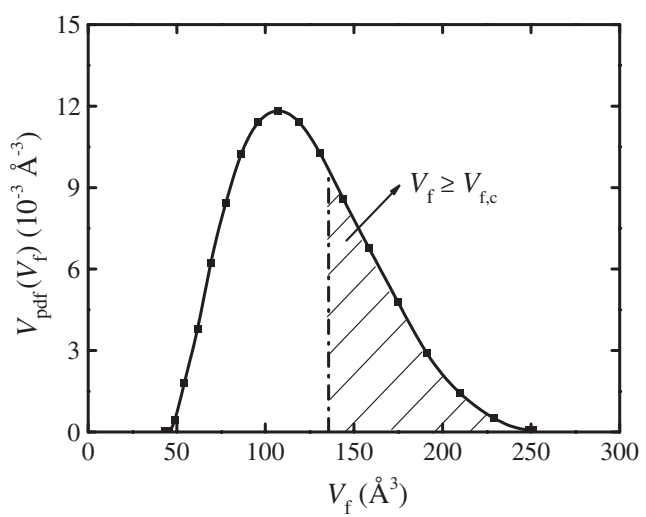

Figure 9. Free-volume distributions $V_{\text {pdf }}\left(V_{f}\right)$ of polystyrene at $403 \mathrm{~K}^{25}$

\section{CONCLUSIONS}

A modified free-volume model has been proposed by estimating polymer hole free volume and critical volume for polymer jumping unit with group contribution method, based on the universal constant of van der Waals volume of polymer repeating unit. All the parameters related to polymer can be calculated by group contributions, and no adjustable parameters are required in this model. Predictions of infinite dilution diffusion coefficients in polymers were consistent with experimental results over a considerable temperature range. For the studied polymers, logarithm of infinite dilution diffusion coefficients of methanol, acetates, alkanes and aromatics were linearly dependent on inverse polymer hole free volume. Moreover, the correlation between PALS measurements and the free-volume theory was developed with the consideration that the ratio of hole free volume to total free volume in polymer from microscopic view should be equal to that from macroscopic view. The analysis of hole size distribution from PALS results proved the reliability of this model. 
Acknowledgments. We gratefully acknowledge the financial assistance from the Talent-Recruiting Foundation of China University of Petroleum (No. Y080439), China Postdoctoral Science Foundation (No. 200801218), the Major State Basic Research Development Program of China (973 Program) (No. 2003CB615701) and the National Natural Science Foundation of China (No. 20676068).

\section{LIST OF SYMBOLS}

$C$ cumulative distribution

$D_{0}$ constant pre-exponential factor $\left[\mathrm{cm}^{2} \cdot \mathrm{s}^{-1}\right]$

$D_{01}$ constant pre-exponential factor when $E^{*}$ is set to equal to zero $\left[\mathrm{cm}^{2} \cdot \mathrm{s}^{-1}\right]$

$D^{\infty}$ infinite dilution diffusion coefficient $\left[\mathrm{cm}^{2} \cdot \mathrm{s}^{-1}\right]$

$E^{*}$ energy required to overcome attractive forces from neighboring molecules $\left[\mathrm{J} \cdot \mathrm{mol}^{-1}\right]$

$E_{\mathrm{g}}$ molar thermal expansivity of polymer below its glass transition temperature $\left[\mathrm{cm}^{3} \cdot \mathrm{mol}^{-1} \cdot \mathrm{K}^{-1}\right]$

$E_{1}$ molar thermal expansivity of polymer above its glass transition temperature $\left[\mathrm{cm}^{3} \cdot \mathrm{mol}^{-1} \cdot \mathrm{K}^{-1}\right]$

$f_{\mathrm{g}}$ polymer fractional free volume at its glass transition temperature

$F$ ratio of free volume available for transport to the total free volume via PALS

$M$ molar mass of group increment $\left[\mathrm{g} \cdot \mathrm{mol}^{-1}\right.$ ]

$M_{2}$ molecular weight of polymer structural unit $\left[\mathrm{g} \cdot \mathrm{mol}^{-1}\right]$

$N_{\mathrm{A}}$ Avogadro constant $\left[\mathrm{mol}^{-1}\right]$

$R$ gas constant $\left[\mathrm{J} \cdot \mathrm{mol}^{-1} \cdot \mathrm{K}^{-1}\right]$

$T$ temperature [K]

$T_{\mathrm{g} 2}$ polymer glass transition temperature $[\mathrm{K}]$

$\tilde{v}_{\mathrm{W}}$ molar van der Waals volume of group increment $\left[\mathrm{cm}^{3} \cdot \mathrm{mol}^{-1}\right]$

$V$ polymer specific volume via Simha-Somcynsky EOS $\left[\mathrm{cm}^{3} \cdot \mathrm{g}^{-1}\right]$

$\tilde{V}\left(T_{\mathrm{g} 2}\right)$ polymer molar volume at its glass transition temperature $\left[\mathrm{cm}^{3} \cdot \mathrm{mol}^{-1}\right]$

$\hat{V}_{2}^{*}$ specific critical hole free volume of polymer segment required for jump $\left[\mathrm{cm}^{3} \cdot \mathrm{g}^{-1}\right]$

$V_{\text {f }}$ hole volume $\left[\AA^{3}\right]$

$V_{\mathrm{f}, \mathrm{c}}$ critical hole volume $\left[\AA^{3}\right]$

$V_{\mathrm{f}, \max }$ maximum hole volume $\left[\AA^{3}\right]$

$\tilde{V}_{\mathrm{g}}$ polymer molar volume below its glass transition temperature $\left[\mathrm{cm}^{3} \cdot \mathrm{mol}^{-1}\right]$

$\tilde{V}_{1}$ polymer molar volume above its glass transition temperature $\left[\mathrm{cm}^{3} \cdot \mathrm{mol}^{-1}\right]$

$\hat{V}_{\mathrm{o}}(0)$ polymer specific volume at $0 \mathrm{~K}\left[\mathrm{~cm}^{3} \cdot \mathrm{g}^{-1}\right]$

$\tilde{V}_{\mathrm{o}}(0)$ polymer molar volume at $0 \mathrm{~K}\left[\mathrm{~cm}^{3} \cdot \mathrm{mol}^{-1}\right]$

$\hat{V}_{\mathrm{FH} 2}$ polymer specific hole free volume $\left[\mathrm{cm}^{3} \cdot \mathrm{g}^{-1}\right]$

$\tilde{V}_{\mathrm{W}}$ molar van der Waals volume of polymer structural unit $\left[\mathrm{cm}^{3} \cdot \mathrm{mol}^{-1}\right]$

$V_{\text {pdf }}\left(V_{\mathrm{f}}\right)$ free-volume probability density function from PALS $\left[\AA^{-3}\right]$

$y$ fraction of occupied sites in Simha-Somcynsky EOS

\section{Greek letters}

$\xi$ ratio of critical molar volume of solvent jumping unit to that of polymer jumping unit

$\rho_{2}$ polymer density $\left[\mathrm{g} \cdot \mathrm{cm}^{-3}\right]$

Received: February 26, 2009

Accepted: August 10, 2009

Published: September 28, 2009

\section{REFERENCES}

1. L. Masaro and X. X. Zhu, Prog. Polym. Sci., 24, 731 (1999).

2. H. Fujita, Fortschr. Hochpolym. Forsch., 3, 1 (1961).

3. J. S. Vrentas and J. L. Duda, J. Polym. Sci., Polym. Phys. Ed., 15, 403 (1977).

4. J. S. Vrentas and J. L. Duda, J. Polym. Sci., Polym. Phys. Ed., 15, 417 (1977).

5. H. Fujita and Y. Einaga, Polymer, 31, 1486 (1990).

6. J. M. Zielinski and J. L. Duda, AIChE J., 38, 405 (1992).

7. J. S. Vrentas and C. M. Vrentas, Macromolecules, 27, 4684 (1994).

8. J. S. Vrentas and C. M. Vrentas, Macromolecules, 27, 5570 (1994).

9. S. U. Hong, Ind. Eng., Chem. Res., 34, 2536 (1995).

10. S. U. Hong, Ind. Eng., Chem. Res., 36, 501 (1997).

11. J. S. Vrentas and C. M. Vrentas, Eur. Polym. J., 34, 797 (1998).

12. B. G. Wang, T. Yamaguchi, and S. I. Nakao, J. Polym. Sci., Part B. Polym. Phys., 38, 846 (2000).

13. T. Yamaguchi, B. G. Wang, E. Matsuda, S. Suzuki, and S. I. Nakao, J. Polym. Sci., Part B: Polym. Phys., 41, 1393 (2003).

14. M. H. Cohen and D. Turnbull, J. Chem. Phys., 31, 1164 (1959).

15. D. Turnbull and M. H. Cohen, J. Chem. Phys., 34, 120 (1961).

16. H. L. Lv and B. G. Wang, J. Polym. Sci., Part B: Polym. Phys., 44, 1000 (2006).

17. B. G. Wang, H. L. Lv, and J. C. Yang, Chem. Eng. Sci., 62, 775 (2007).

18. H. L. Lv, B. G. Wang, and J. C. Yang, Polym. J., 39, 1167 (2007).

19. P. M. Budd, N. B. Mckeown, and D. Fritsch, J. Mater. Chem., 15, 1977 (2005).

20. J. D. Ferry, in "Viscoelastic Properties of Polymers," 3rd ed., Wiley, New York, 1980.

21. D. W. van Krevelen, in "Properties of Polymers," 3rd ed., Elsevier, Amsterdam, 1990.

22. M. L. Williams, R. F. Landel, and J. D. Ferry, J. Am. Chem. Soc., 77, 3701 (1955).

23. R. N. Haward, J. Macromol. Sci.-Revs. Macromol. Chem., C4, 191 (1970).

24. A. Bondi, in "Physical Properties of Molecular Crystals, Liquids and Glasses,” Wiley, New York, 1968.

25. J. Liu, Q. Deng, and Y. C. Jean, Macromolecules, 26, 7149 (1993).

26. G. Dlubek, D. Kilburn, V. Bondarenko, J. Pionteck, R. KrauseRehberg, and M. A. Alam, Macromol. Symp., 210, 11 (2004).

27. D. Kilburn, G. Dlubek, J. Pionteck, D. Bamford, and M. A. Alam, Polymer, 46, 869 (2005).

28. G. Dlubek, J. Non-Cryst. Solids, 352, 2869 (2006).

29. D. S. Hu, C. D. Han, and L. I. Stiel, J. Appl. Polym. Sci., 33, 551 (1987).

30. D. Arnould and R. L. Laurence, Ind. Eng. Chem. Res., 31, 218 (1992).

31. J. S. Vrentas, C. M. Vretnas, and N. Faridi, Macromolecules, 29, 3272 (1996).

32. W. H. Jiang, H. Liu, and S. J. Han, Acta Chim. Sinica, 59, 34 (2001).

33. W. H. Jiang, H. Liu, H. J. Hu, and S. J. Han, Eur. Polym. J., 37, 1705 (2001).

34. A. Thran, G. Kroll, and F. Faupel, J. Polym. Sci., Part B: Polym. Phys., 37, 3344 (1999).

35. P. A. Rodgers, J. Appl. Polym. Sci., 48, 1061 (1993). 